\title{
Review: vaginal signs and symptoms perform poorly in diagnosing vaginal candidiasis, bacterial vaginosis, and vaginal trichomoniasis
}

Anderson MR, Klink K, Cohrssen A. Evaluation of vaginal complaints. JAMA 2004;291:1368-79.

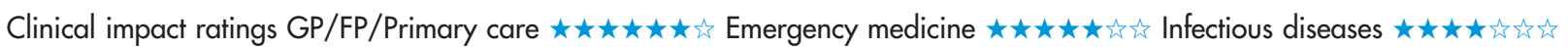

In patients with vaginitis, how do individual symptoms, physical examination signs, and laboratory tests perform in diagnosing vaginal candidiasis (VC), bacterial vaginosis (BV), and vaginal trichomoniasis (VT)?

\section{METHODS}

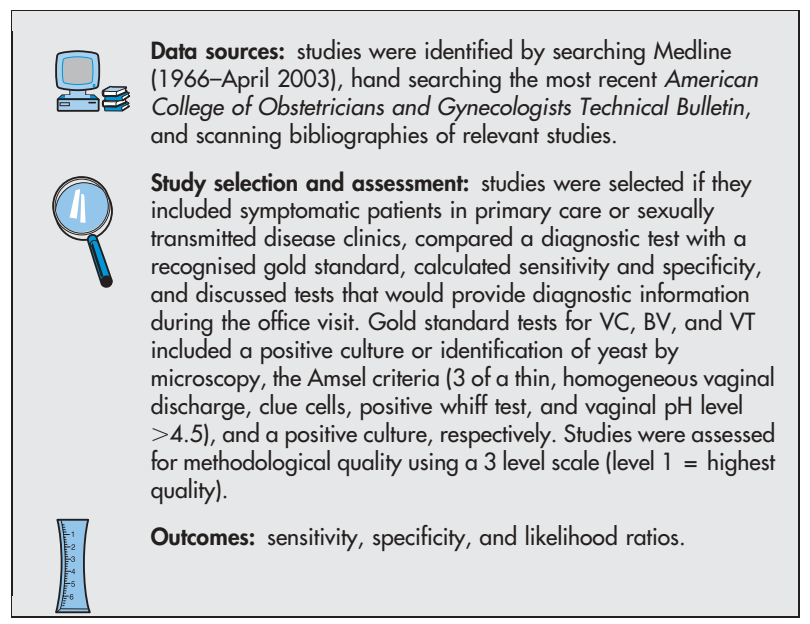

Test characteristics of symptoms, signs, and laboratory tests for diagnosing vaginal candidiasis (VC), bacterial vaginosis (BV), and vaginal trichomoniasis (VT)*

\begin{tabular}{|c|c|c|c|c|c|}
\hline Tests & Diagnosi & $s$ Sensitivit & y Specificity & $+L R$ & $-\mathrm{LR}$ \\
\hline \multicolumn{6}{|l|}{ Individual symptoms } \\
\hline Cheesy discharge & VC & $65 \%$ & $73 \%$ & 2.4 & 0.48 \\
\hline Odour & BV & $97 \%$ & $40 \%$ & 1.6 & 0.07 \\
\hline Itching & VC & $27 \%$ & $92 \%$ & 3.3 & 0.79 \\
\hline Redness & VC & $28 \%$ & $86 \%$ & 2.0 & 0.84 \\
\hline External dysuria & VC & $33 \%$ & $85 \%$ & 2.2 & 0.79 \\
\hline Previous yeast infection & VC & $35 \%$ & $90 \%$ & 3.3 & 0.72 \\
\hline \multicolumn{6}{|l|}{ Physical examination signs } \\
\hline $\begin{array}{l}\text { White, curdy } \\
\text { discharge }\end{array}$ & VC & $16 \%$ & $97 \%$ & 6.1 & 0.86 \\
\hline Yellow discharge & BV & $60 \%$ & $85 \%$ & 4.1 & 0.46 \\
\hline Yellow discharge & VT & $89 \%$ & $93 \%$ & 14 & 0.12 \\
\hline Moderate discharge & BV & $62 \%$ & $75 \%$ & 2.5 & 0.5 \\
\hline Profuse discharge & BV & $4 \%$ & $99 \%$ & 3.0 & 0.98 \\
\hline High cheese odour & BV & $78 \%$ & $75 \%$ & 3.2 & 0.30 \\
\hline Redness or oedema & VT & $18 \%$ & $97 \%$ & 6.4 & 0.85 \\
\hline Any inflammation & VC & $46 \%$ & $78 \%$ & 2.1 & 0.69 \\
\hline \multicolumn{6}{|l|}{ Laboratory } \\
\hline $\begin{array}{l}\text { Normal pH level } \\
(<4.9)\end{array}$ & VC & $71 \%$ & $90 \%$ & 7.2 & 0.32 \\
\hline Gram stain & VC & $65 \%$ & $100 \%$ & 31 & 0.36 \\
\hline $\begin{array}{l}\text { Bacilli with corkscrew } \\
\text { motility }\end{array}$ & BV & $65 \%$ & $100 \%$ & 44 & 0.36 \\
\hline Positive whiff test & VT & $67 \%$ & $65 \%$ & 1.9 & 0.51 \\
\hline Wet mount & VT & $67 \%$ & $100 \%$ & 100 & 0.34 \\
\hline
\end{tabular}

For correspondence: Dr $\mathrm{M} R$ Anderson, Albert Einstein College of Medicine, Bronx, NY, USA. andersonma@aol.com

Source of funding: no external funding.

\section{MAIN RESULTS}

18 articles met the selection criteria. The quality of the studies ranged from level 2 to 3 . The test characteristics of individual symptoms and physical examination signs are in the table. Laboratory tests performed better than signs and symptoms in diagnosing VC, BV, and VT (table).

\section{CONCLUSIONS}

In patients with vaginitis, individual symptoms and physical examination signs do not perform well in diagnosing vaginal candidiasis, bacterial vaginosis, and vaginal trichomoniasis. Laboratory tests perform better for diagnosing these conditions.

Abstract and commentary appear in ACP Journal Club.

\section{Commentary}

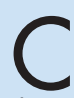

ommon, non-life-threatening problems are often the least studied areas of medicine, despite the overall burden of disease that they cause. At last, we are beginning to accumulate evidence to guide diagnosis and management in these areas. The review by Anderson et al presents a summary of the available evidence on the accuracy of the symptoms, signs, and office laboratory tests for diagnosing vaginal complaints.

With the exception of white curdy discharge, which helps to rule in the diagnosis of $\mathrm{VC}$; yellow discharge, which can indicate the presence of either $\mathrm{BV}$ or $\mathrm{VT}$; and redness or oedema, which can also indicate $\mathrm{VT}$, these symptoms and signs are only moderately helpful in determining whether a patient has any of these vaginal conditions. The absence of symptoms and signs is even less helpful in ruling out disease, with only the absence of odour or yellow discharge ruling out BV. Office laboratory tests perform better because they rule in the disease if they are positive, but they do not rule out the disease if they are negative. Furthermore, many clinicians do not have the skills, time, or equipment to use these tests.

Several questions remain after reading this review: Could there be combinations of symptoms and signs that might better rule in or rule out the diagnosis? How does this information combine with more definitive testing, such as culture of a high vaginal swab? What is the treatment threshold for these conditions? Might it be better to treat on clinical suspicion, and test only those patients who fail a course of treatment? Primary care gynaecology requires more research to guide clinical decision making in this area.

Jenny Doust, BMBS University of Queensland Brisbane, Queensland, Australia 